\title{
Mathematics learning opportunities when playing a Tower Defense Game
}

\author{
Aura Hernández-Sabaté ${ }^{1}$, Meritxell Joanpere ${ }^{1}$, Núria Gorgorió ${ }^{1}$, Lluís Albarracín ${ }^{1}$ \\ $1^{*}$ Universitat Autònoma de Barcelona \\ aura@cvc.uab.cat, meritxell.joanpere@gmail.com, \{nuria.gorgorio, \\ Iluis.albarracin\}@uab.cat
}

\begin{abstract}
A qualitative research study is presented herein with the purpose of identifying mathematics learning opportunities in students between 10 and 12 years old while playing a commercial version of a Tower Defense game. These learning opportunities are understood as mathematicisable moments of the game and involve the establishment of relationships between the game and mathematical problem solving. Based on the analysis of these mathematicisable moments, we conclude that the game can promote problem-solving processes and learning opportunities that can be associated with different mathematical contents that appears in mathematics curricula, thought it seems that teacher or new game elements might be needed to facilitate the processes.
\end{abstract}

Keywords: Tower Defense game, learning opportunities, mathematics, problem solving, game design;

\section{Introduction}

The chances of innovation in mathematics classrooms have increased with the arrival of digital content and support, although the potential of these resources has not been fully explored yet. The progress of technology has brought the development of new tools, such as virtual learning environments [1], dynamic geometry software, like Geogebra or Cabri, or programming environments that have evolved from LOGO to Scratch. The examples shown above have already been successfully introduced to school classrooms.

In addition, the emergence of video games in households has triggered the development of a great number of video games for the purpose of promoting the learning of mathematics [2][3][4]. This has resulted in a general improvement of students' motivation and marks [5]. This kind of video games is usually centered on a specific item of mathematical content, but they do not encourage mathematical competence acquisition such as problem-solving. However, these video games are not specifically designed for entertainment and therefore do not offer the same level of stimulation as commercial video games, carefully devoted to the player's entertainment [6].

From an educational point of view, the latter are not interesting merely due to their appeal to teenagers, but for many other reasons. Some commercial video games such as puzzle-type games, strategy video games or real-life simulators represent an intellectual challenge for the player. This type of games in particular compels players to interpret information that is provided in different ways and requires high levels of comprehension. Playing games is based on continuous decisionmaking processes that force the player to elaborate specific strategies and that answer to the player's actions and decisions immediately, giving instant feedback. For this reason we consider it worth noting that some commercial video games are mathematically interesting in themselves and may foster processes equivalent to problem-solving in complex contexts.

The potential of commercial video games as an educational tool in the field of Mathematics Education has not been widely researched yet. The first studies have observed evidences showing that some features in video games can produce a positive impact on the students' logical and strategic reasoning skills [7], although the effectiveness of digital game-based learning is still to be proven by further research [8].

From our point of view, we acknowledge the fact that commercial video games are not designed to be used directly as educational tools. In addition, there is a great diversity of commercial video games and different ways of implementing them in theclassrooms as learning material. For these 
two reasons, we consider the first step should be to identify problem-solving processes in a particular game and detect potential mathematical learning opportunities that may lead to the acquisition of formal educational mathematical content during video game sessions.

In this paper, we present a research study of qualitative-interpretative nature where we explore the didactic possibilities of a real-time strategy video game called Vector Tower Defense 2 (Candystand, 2008). We detected problem-solving processes that allowed us to identify mathematical learning opportunities associated to curricular mathematical content. Moreover, we found that these opportunities combined different aspects, both mathematical content and problemsolving processes. We therefore conclude that the activity of playing a Tower defense game is a complex problem-solving activity.

\section{Video games as an educational tool}

\subsection{Properties of video games as learning tools}

Bishop [9] describes mathematics as a symbolic technology that is characterised by common activities such as counting, locating, measuring, designing and playing, and explains that different mathematical concepts and potentialities take place when carrying out the aforementioned actions. Playing is therefore an activity that constitutes an important part of children's cognitive and social development and, in fact, games have always been an everyday activity. Salen and Zimmerman [10] define game as "a system in which players engage in artificial conflict, defined by rules, that results in a quantifiable outcome" (p. 80). This definition also holds for digital games or video games, with the additional support of a digital platform.

Playing games may feature elements of learning and training, but also relating to bonding and communication. Vygotsky [11] states that children learn from playing with others, which may lead to more complex situations and activities than those they encounter in their everyday life. According to De Guzmán [12], games are linked to the learning of mathematics, since they require relating to a set of rules and prompt the use of techniques that lead to success and allow for the development of complex game patterns, equivalent to mathematical problems.

Video games can be considered effective learning tools in themselves. Connolly, et al. [13] have identified empirical evidence concerning all the learning and behavioural outcomes including knowledge acquisition, perceptual and cognitive, behavioural, affective, motivational, physicological and social outcomes, but with the exception of soft skills.

The video games intrinsic features make them appealing to players and give them great potential as instruments for learning specific strategies and for acquiring knowledge [14]. Charsky [15] considers the essential characteristics of video games to be competition and the presence of objectives, the existence of well-defined rules and the need to make decisions. In addition, they offer the opportunity of playing in simulated environments, and can therefore play an important role in the learning and intellectual development of the players by presenting situations where decision-making is essential [16]. Video games as simulations give players the chance to think, understand, prepare and carry out actions, as well as the possibility of cooperating with other players in massive multiplayer games, working in teams and sharing knowledge and abilities [17]. The fact that video games are designed on the basis of specific rules and objectives added to the direct interaction with a machine both result in the reception of immediate feedback, rendering them an attractive educational tool [18]. The speed of response to the player's actions or to different types of feedback allows the player to adapt and improve his/her performance to achieve the challenges set by the game. Educational video games design has been tested introducing elements such as interaction and feedback elements, a background story, clear rules, objectives and outcomes, combined with educational aspects, though there is not a well defined framework to develop them [19].

Several research studies have shown evidence of the positive effects of video games as learning tools. Rosas et al. [5] have confirmed that the introduction of educational video games to the classroom environment leads to an improvement in the learning motivation of the students, while promoting the acquisition of knowledge of technological nature. The results on knowledge and cognitive skills suggest that training with serious games is more effective than training with conventional instruction methods [20]. However, Sitzmann [21] found that arrangements in which a simulation game was supplemented with other instructional methods yielded higher levels of learning. It is agreed that conclusive results require both gaming and learning characteristics to be considered [13] and require a deeper understanding of the intricate links between learning and 
game mechanics for engagement [22]. Also, teachers often find difficulties in identifying the educational components of a game, as well as integrating the game in the traditional educational process [23].

Up to our knowledge, there is some evidence for the effects of video games on language learning, history, and physical education (specifically exergames), but little support for the academic value of video games in science and math [24].

\subsection{Video games designed for the learning of mathematics}

Aside from commercial video games, some video games are designed for the purpose of learning mathematics. This type of games is generally based on classroom activities modified to suit the new digital environment, or adaptations of table games with mathematical content. Rosas et al. [5] describe a study on several video games that use challenges and riddles to introduce exercises on mathematical content such as numerical sequences, addition and subtraction problems, estimation and recognition of geometrical figures. Results show an increase in students' motivation towards work and an improvement in their grades in relevant fields.

Kebritchi, Hirumi and Bai [3] used a commercial video game designed specifically to foster the learning of mathematics. The latter is based on the formulation of mathematical questions and problems akin to those commonly used in classrooms. Students that used games to prepare for the state exams at the end of the school year obtained better grades than those that followed traditional training. These authors highlight the fact that the students who chose video games over studying were motivated to solve the problems encountered in order to advance in the course of the game and they used more time in preparing their tests than the other students.

Van den Heuvel-Panhuizen, Kolovou and Robitzsch [4] used a dynamic online game designed to exercise early algebra problem solving. This video game proposes a sequence of problems to the students and monitors their progress. Their results show that online work improves their marks in problem-solving, but does so by using strategies that are approached differently in classroom environments, such as in trial-and--error strategy. Chow, Woodford and Maes, [25] used an online version of the game "Deal or not deal" and confirm that students improve their knowledge on expected values in an introductory statistics course at the same time as they improve their overall ability to process information and make logical decisions. Nejem \& Muhanna [26] used a video game that is specifically designed for learning fractions and they observed that students who used the game showed an improved development of their number sense skills.

On the other hand, Panoutsopoulos \& Sampson [8] observed that students engaged in educational activities supported by "The Sims 2 - Open for Business" did not improve their results in relation to the educational objectives of the subject, in comparison to students who did not make use of these games. Neither did they find significant differences in the students' attitudes towards math teaching and learning. This study reveals the need to investigate other general-purpose commercial video games and the different applications for developing educational methodologies adapted to the work promoted in a classroom.

The video games appointed above, designed to learn mathematics, are centered on specific mathematical contents. However, it is worth noting that other mathematical skills and competences that have been widely covered in the literature and are included in educational curricula are not supported by any existing video games. Following this, Bottino, Ferlino, Ott \& Tavella [7] used adaptations of puzzle mindgames such as Mastermind or Battleship and consider these adaptations should have software features like the possibility to backtrack movements, hints to detect movements that may benefit the player, tips or support to visualise the consequences of future decisions. They observed a positive impact of the game on students' logical and strategic reasoning skills and show a new line of work to be considered for the design of video games that support mathematical competences such as problem solving.

Harris, Yuill \& Luckin [27] addressed how video games may be used to effectively facilitate student collaboration on complex logic problems. These authors observed that students with different goal orientations interacted in different ways while solving mathematical problems and concluded that goal-focused instructions could be used to influence the nature and quality of children's partnered interactions, potentially improving long-term academic achievement. 


\section{Mathematical problem solving}

Grugnetti and Jaquuet [28] suggest that in the literature there is no fully consensual definition of what activities could be considered a mathematical problem, on account of the different current formulations of what mathematics actually is. Schoenfeld [29], [30] regards problems as essentially those activities that are not based on repeating routines. In Principles and Standards of the NCTM [31], problem-solving is defined as "engaging in a task for which the solution method is not known in advance" (p. 52). This is also present in the definition given by Lesh and Zawojewski [32]: "A task, or goal-directed activity, becomes a problem (or problematic) when the problemsolver, which may be a collaborating group of specialists, needs to develop a more productive way of thinking about the given situation" (p. 31).

Regarding the problem-solving process, Lester \& Kehle [33] suggest that reasoning and/or higher order thinking must be present during mathematical problem solving. Hence, it seems that in the essence of a mathematical problem lies the need to develop knowledge or processes previously unknown during the mathematical activity.

Pursuant to Pólya [34], the mathematical problem-solving process is divided into: a) understanding the problem; b) devising a plan; c) carrying out the plan; and d) looking back. Pólya's work has so influenced the community of mathematical education researchers that the different models describing problem-solving processes follow the same scheme. According to Verschaffel, Greer and De Corte [35], problem solving involves the following stages, although not always in linear fashion: creating a mental image of the problem; planning how to solve the problem; interpreting the obtained data and developing an answer; evaluating the solution.

Engle \& Conant [36] establish an abstraction of the characteristics that should be fulfilled to achieve a mathematics class in which sense-making can be studied with students.

- $\quad$ students should be encouraged to solve problems;

- students should have the authority to choose the direction in which these problems are solved;

- the work of these students is to be evaluated by other members of the group, and the rules should be adhered to;

- $\quad$ students will have the necessary resources to perform whatever is required of them.

One of the basic factors in problem solving by students is their context. According to Van den Heuvel-Panhuizen [37], giving problems a real context can render them more accessible and suggest strategies to students. At the same time, he considers that informal mathematics prevail in problem solving in everyday life and the workplace while, on the contrary, formal mathematics predominate in the classroom.

Cobb and Whitenack [38] consider that mathematical learning is a process of conceptual selforganisation and inculturation, so that a mathematical learning opportunity could be understood as a situation in which students are faced with the chance to reorganise their conceptual structures or relate them to new ways of approaching problem solving or other types of mathematical activities. These mathematical learning opportunities should be achieved in specific learning instances by mathematising the situations they appear in. In the framework of this study, we consider that a strategy video game can act to provide these opportunities for mathematical learning, and that a teacher's involvement or a set of tools that turn a video game into a serious game is what enables them to be mathemetised.

\section{Methodology}

In this section we describe the goal of these study, the characteristics of the video game used, participants and data collection and the analysis method used.

\subsection{The goal of the study}

In this study we have used a video game of the Tower Defense genre to detect the game processes associated with mathematical concepts and procedures relevant to students aged from 10 to 12 years. The main goal of the study is use this characterisation of the students' gameplay as a problem solving activity to identify mathematical learning opportunities that can be promoted while playing. 
The final aim of our project is to design mathematical tools that could be incorporated to a new tower defense game to be used in mathematical classroms as a didactical tool.

\subsection{Description of the video game used}

Tower Defense is a sub-genre of real-time strategy video games. The goal is to prevent enemy units, who arrive in waves, from crossing the map and attacking our base. To achieve this, defense towers have to be built which can assault enemy units as they pass. Funds are earned for eliminating each enemy unit, and these must be used to build or reinforce towers, so that strategic considerations are based on the choice and placement of the towers and resource management. There is a great variety of games in this genre but, in all of them, both the enemies and the defensive towers have different offensive and defensive skills, and each has a different cost.

The video game used in the qualitative study is Vector Tower Defense 2, by Candystand. It has been accessible on the web since 2008. The aesthetics of the game is neutral, and there are no elements of violence, making it suitable for students from the age of 10 . In this game, the enemy has to move along a specific path, and players have a large variety of towers, upgrades and bonus points, prompting them to exploit their strategic skills to the limit. One of the features of this video game design is that it includes bonus points at the end of each wave of enemy attack - a specific percentage of the banked money - so that choosing the right moment to invest in new towers is yet another element of the game's strategic aspects.

Figure 1 shows a screenshot at a specific moment of a game. In the centre is the path the enemy move along, and various towers which attack them. The sidebars provide various details, such as the score, available funds, and the type of towers available at a given time in the game and their features.

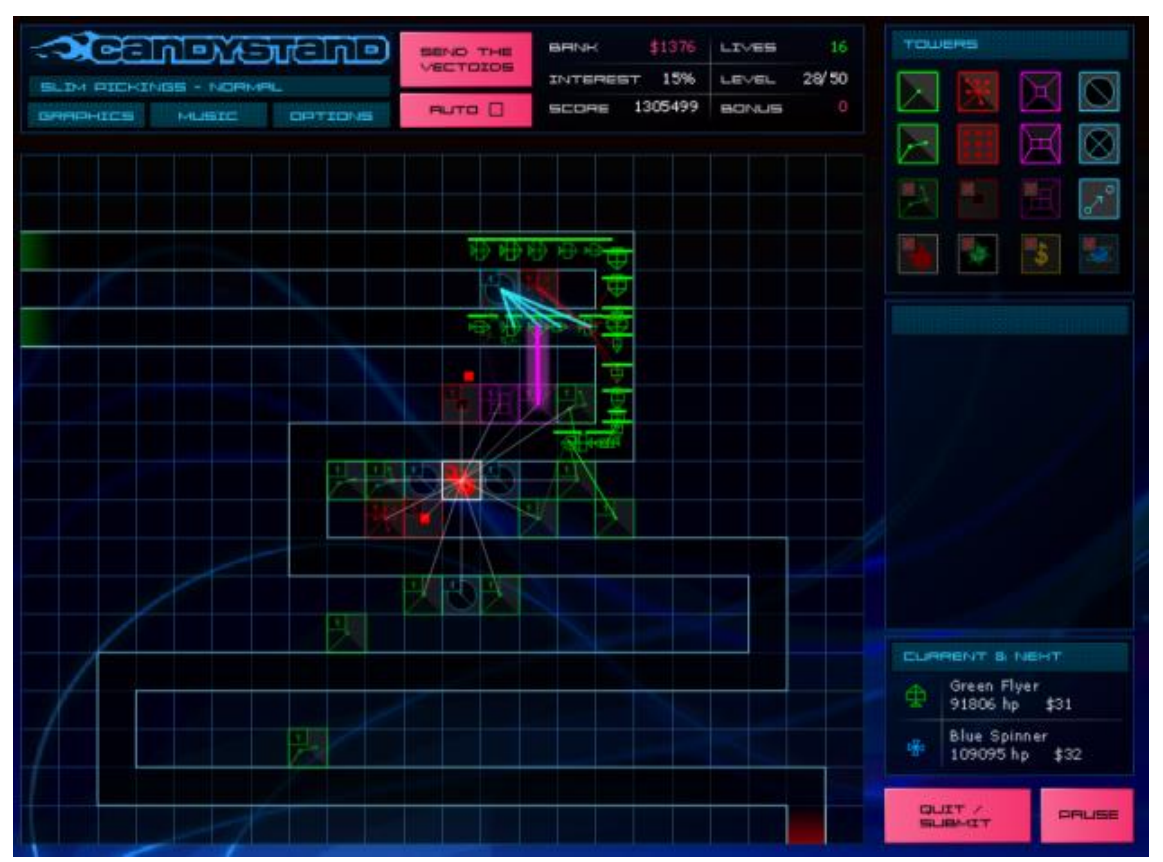

Figure 1. A screenshot of Vector Tower Defense 2 (Candystand, 2008)

The game provides players with information on different levels. The panel containing the most information is the game map, which takes up the whole central part. This area shows the path the enemy must take the position of the towers, the shots taken from the towers and the bonus objects on them.

General information is provided at the top of the screen, such as the number of the next enemy wave, available funds, the interest percentage they generate and the lives remaining. The different towers that can be used at each moment are shown on the right, including a description of them and details of the enemy. Figure 2 displays a description of one of the towers, showing the cost, the damage it inflicts in each attack and the bonus points for the various types of towers expressed as percentages. 


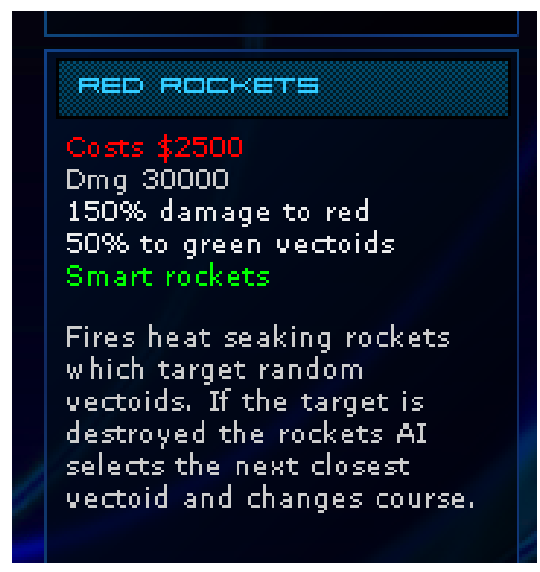

Figure 2. Description of the features of one of the towers in the game

\subsection{Participants and data collection}

To identify problem-solving processes in the game and detect potential mathematical learning opportunities, 6 pairs of students were recorded while playing Vector Tower Defense 2. We asked students to play a game and try to reach the highest level possible was requested. Previously they received a basic understanding of the basic mechanics of the game, like how to choose and place towers. By playing in pairs, the decisions and strategies adopted were made explicit, as they had to be agreed on by the two players. Half of the pairs were students aged 10, while the other half were aged 12. We considered that students of different ages can develop different game strategies and we wanted to explore this possibility. Figure 3 shows a frame of a video done during a session. For each session we captured the screen play (left-hand side of Figure 3), the gestures they did on the screen (top-right-hand side of Figure 3), and the interaction between the students (bottom-righthand side of Figure 3) and we synchronized them to show at once.

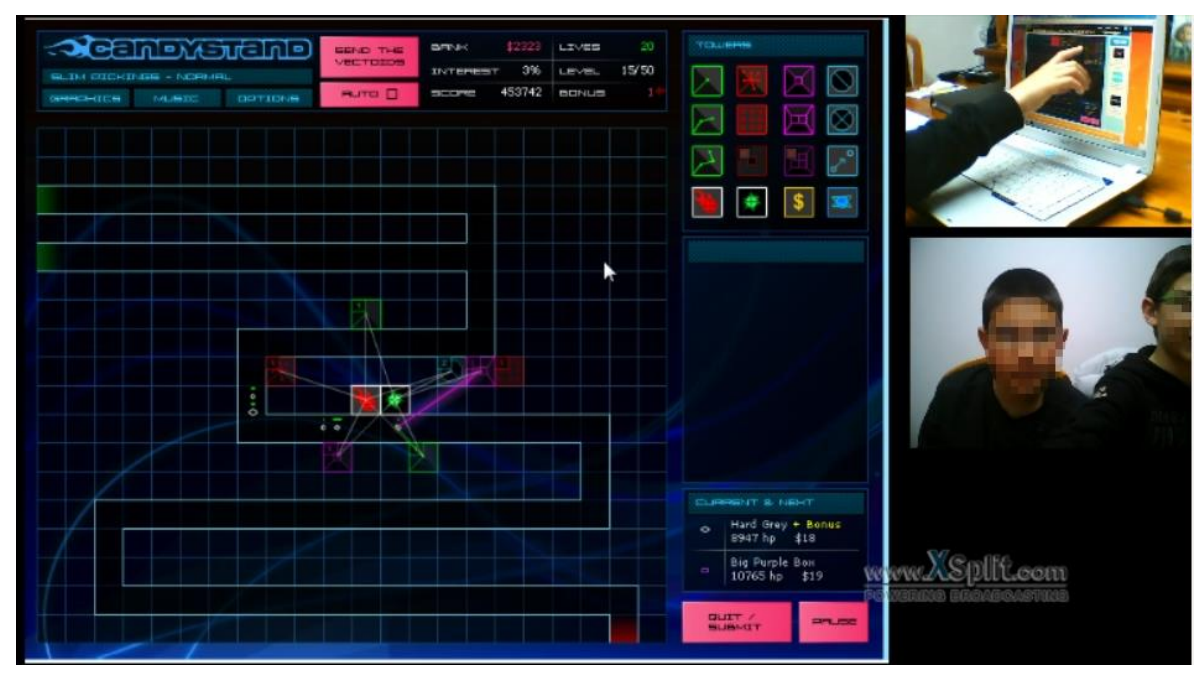

Figure 3. A sample recording of the students playing

The 6 video recordings contain the whole game played by the students. The duration of these games ranges from 26 minutes to 1 hour and 8 minutes. Table 1 summarizes, for each pair of players, the age of the students, the game duration and the maximum level achieved. 
Table 1. Video characteristics

\begin{tabular}{c|c|c|c}
\hline & Age & Game duration & $\begin{array}{c}\text { Maximum level } \\
\text { achieved }\end{array}$ \\
\hline Pair 1 & 10 & $26 \mathrm{~min}$ & 27 \\
\hline Pair 2 & 10 & $1 \mathrm{~h} \mathrm{08} \mathrm{min}$ & 39 \\
\hline Pair 3 & 10 & $54 \mathrm{~min}$ & 34 \\
\hline Pair 4 & 12 & $47 \mathrm{~min}$ & 35 \\
\hline Pair 5 & 12 & $42 \mathrm{~min}$ & 34 \\
\hline Pair 6 & 12 & $51 \mathrm{~min}$ & 40 \\
\hline
\end{tabular}

\subsection{Data analysis}

In order to analyse the data, we created a text file for each pair of players of the transcript of their conversation during the game, as well as the annotations of their game actions and comments on non-verbal behaviour, which allowed us to understand their conversation regarding the development of the game.

The data were analysed from a qualitative-interpretative point of view. For that, the transcripts were organised in chapters. Each chapter corresponds to a continuous period of time in which players approach a particular question.

The analysis was decomposed into two phases, a first one characterising the chapters and a second one determining the nature of the mathematical learning opportunities identified.

For the first stage, we considered those categories related to mathematical problem-solving together with other emergent categories reflecting aspects directly related to the game. These categories are shown in Table 2.

Table 2. Analysis categories

\begin{tabular}{|c|c|c|}
\hline Problem-Solving stages & Analysis Categories & Description \\
\hline \multirow[t]{3}{*}{ Understanding the problem } & Previous experience & $\begin{array}{l}\text { Experiences or knowledge players have acquired } \\
\text { before }\end{array}$ \\
\hline & Opinion & $\begin{array}{l}\text { Players appreciated several aspects of the game } \\
\text { they consider relevant to modifying their } \\
\text { decisions }\end{array}$ \\
\hline & Prediction & $\begin{array}{l}\text { Players foresaw what would happen in the near } \\
\text { future }\end{array}$ \\
\hline Devising a plan & Planning & $\begin{array}{l}\text { Players organized their following actions to be } \\
\text { done in the following rounds }\end{array}$ \\
\hline Carrying out the plan & Decision-making & $\begin{array}{l}\text { Players agreed on a common approach and they } \\
\text { executed it }\end{array}$ \\
\hline \multirow[t]{3}{*}{ Looking back } & Justification & Players justified an action carried out \\
\hline & Thinking process & $\begin{array}{l}\text { Players thought about the decisions that lead to } \\
\text { the present game situation }\end{array}$ \\
\hline & Reasoning & $\begin{array}{l}\text { Players developed an argument for future } \\
\text { decisions }\end{array}$ \\
\hline \multirow[t]{2}{*}{ Technical } & Technical question & $\begin{array}{l}\text { Players asked the researcher about game aspects } \\
\text { unknown to them }\end{array}$ \\
\hline & $\begin{array}{l}\text { Response to a } \\
\text { technical question }\end{array}$ & $\begin{array}{l}\text { Players and researcher discussed about the } \\
\text { response to a technical question }\end{array}$ \\
\hline
\end{tabular}

The analysis procedure was the following: each video recording was analysed by two researchers separately, out of a total of four researchers. After that, the four researchers exchanged the categorisation of the data to share their analysis and determine key characteristics to define each kind of episode. We consider that the analysis is robust since while analysing new gameplays, some categories are overloaded and new categories are not necessary. This categorization allows for making plots that show the activity of the students during each game. Figure 4 shows the categorisation of each episode of a particular gameplay. 


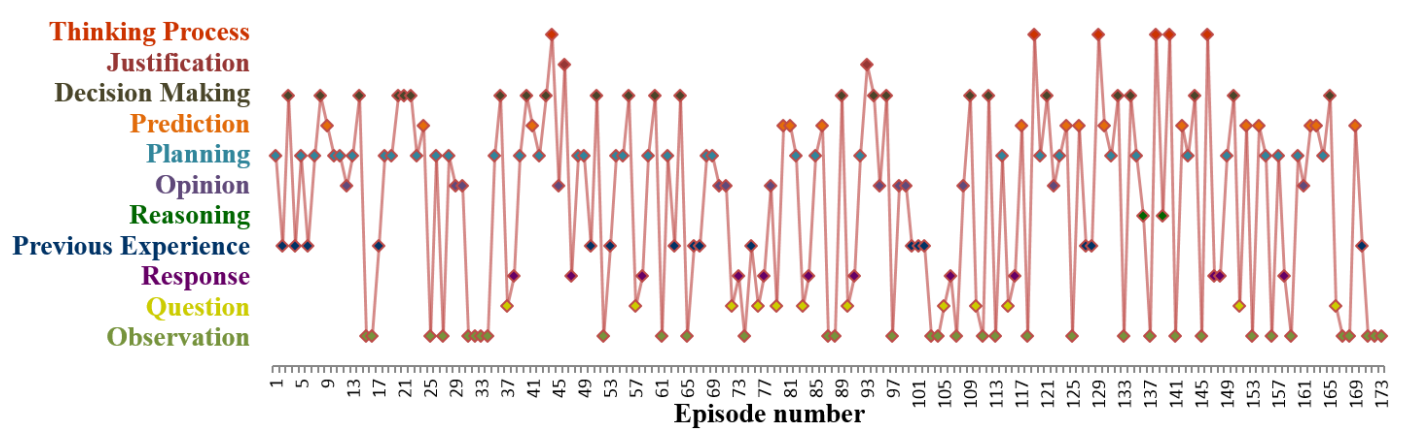

Figure 4. Categorisation of the episodes of one video gameplay

Once the plots were done, the second phase consisted of identifying mathematical learning opportunities. We understand that these opportunities appear in cycles of observation-planningdecision-making since they follow the outline of problem-solving and involve the need to generate new knowledge about the game. Figure 4 shows 19 of the mentioned cycles. We also observed learning opportunities during the phases of thinking and justification, where we identified 8 of them. The nature of these learning opportunities is the basis of our results which we present in the following section.

\section{Results of the study}

The results obtained are presented in two subsections: the results we identified regarding mathematical learning opportunities and the ones related to the type of mathematical work promoted by the video game.

\subsection{Mathematical learning opportunities}

A qualitative data analysis has allowed us to determine several mathematical learning opportunities that arised from the study of problem-solving procedures during the game. We observed that students have to deal with challenging situations and try to overcome them by following patterns similar to those of mathematical problem-solving procedures. Indeed, in all the opportunities identified, comprehension and the use of mathematical items seem to be the key to successfully approach these challenges. The results shown in this subsection correspond to the different types of learning opportunities identified. For each type, we show an illustrative example from our analysis.

\section{Type 1. Geometrical aspects}

The following assertion done by one student is an example of his growing interest in finding out about the features of the towers. This assertation belongs to a part of a chapter named in the analysis as planning.

Student 1: Hey! How come? Oh, I see... I'd better place this one here because it's got a bigger radius. It's more powerful and has a bigger radius. (Placing a red tower in an area which doesn't have one.)

Specifically, the student appears to have checked details of the tower's damage capabilities before deploying it strategically in an area where he considers it to be useful. In this analysis, it is necessary that the student considers distancies for the reach of the towers as well as the shape of the way the enemies pass in order to be able to decide the best towers position. Thus, we observe that, not only does Student 1 start using the game elements intuitively and not reflexively, but he also develops an interest in finding out details of its elements at a certain point in the game. In particular, in this statement we can observe that position and operating range of a tower seem to be essential for the student, since the need to use localization and measurement arises throughout the game.

\section{Type 2. Relationship among variables}

In the following exchange, in the final part of the game of a couple, we observe the same student relating the damage capabilities of the towers to enemy lives: 
Student 1: Now they're destroying me because the hp thing (the enemy's amount of life) has shot up "loads"... to 10,000 or something like that, and none of the towers can kill like that; not even reinforced.

Researcher: You mean the amount of life?

Student 1: Yes - those creatures' lives are much bigger than any tower attack.

Another student, who had just lost control of the game, quickly places a tower and, on seeing the consequences of not having thought his decision through properly, comments:

Student 2: By placing it here, it cuts off half the radius, and it hardly zapped any of them. (Meaning that the last red tower he had placed in haste couldn't make use of the whole radius.) Maybe I should have put it here... (while pointing to a different part of the screen). The above assertation belongs to a part of a chapter named in the analysis as decision-making. Indeed, in these two statements we can observe that the need arises to compare the amount of damage each tower can inflict on the life expectancy of enemies, which varies in time with the interaction of towers and enemies. In this way, the students are positioned in front of the behaviour of a function which conditions their game success possibilities. The sentence of the second student shows that this difficulty is not unique, since the position of the towers is a factor affecting numerical relation. For that, we observe that an opportunity arises to introduce the study of functions and promote the analysis of complex situations where several mathematical elements step in.

\section{Type 3. Arithmetical problem-solving}

The next episode is an example of the kind of situation which crops up throughout the students' games, in which they decide to wait until they have sufficient funds in order to place a certain kind of tower. Again, it is an example of an assertation of a part of a chapter named decision making:

Student 3: When we can use a red one... (pointing to the upcoming enemy) because all of them are going to be red.

Student 4: Yes.

Student 3: The red one... when you can.

Student 4: Right, right, but... let's see... we're up to 197.

This exchange between Student 3 and Student 4 reveals the need to glean mathematical-type information directly affecting the game. Further, the following exchange then takes place between these same two students and the researcher:

Student 4: Yes, the third green here. It's really useful to have.

Researcher: How long before you can get it?

Student 4: This one?

Researcher: Yes, this one (pointing to the screen).

Student 4: If each dummy earns us $\$ 22$, we still have a way to go.

This type of learning opportunity is related to arithmetical problem-solving and shows that this video game could be a good environment in which to develop these problems and give a real context that is experienced by the students as motivating mathematical work. This last episode between Students 3 and 4 shows that the students don't feel the need to mathematically solve one of the situations that has arisen in the game. This leads us to conclude that the commercial video game promotes a highly specific type of mathematical thinking which should be reinforced using game-related tools or activities in order to turn the game into a learning tool.

\section{Type 4. Commensurability}

The following exchange pinpoints the difficulty students have when they realise that tower damage varies in terms of the type of enemy:

Student 5: Now, how much damage can it do in this round? It's got... I don't know - the damage it did at the beginning plus...

Student 6: $50 \%$ more?

Student 5: This time it's 50\% more, and, in the next round? (which will feature enemies worth a different number of bonus points).

In this last chapter, we observe the introduction of another mathematical concept, the use of percentages and direct commensurability. This type of mathematical learning opportunity is clearly induced by the feature design of the video game. In particular, the towers obtain a bonus for inflicting damage on specific enemies, producing game situations that do not go unnoticed by the students. 
Summaryzing the results of the study, Table 3 shows the number of mathematics learning opportunities of each type for each pair of students.

Table 3. Number of Mathematical Learning Oportunities identified

\begin{tabular}{c|c|c|c|c|c}
\hline Vídeo & $\begin{array}{c}\text { Total number } \\
\text { of MLO }\end{array}$ & $\begin{array}{c}\text { Type 1 } \\
\text { Geometry }\end{array}$ & $\begin{array}{c}\text { Type 2 } \\
\text { Relationships }\end{array}$ & $\begin{array}{c}\text { Type 3 } \\
\text { Arithmetics }\end{array}$ & $\begin{array}{c}\text { Type 4 } \\
\text { Proportionality }\end{array}$ \\
\hline Pair 1 & 17 & 6 & 2 & 8 & 1 \\
\hline Pair 2 & 27 & 12 & 4 & 7 & 4 \\
\hline Pair 3 & 24 & 9 & 5 & 8 & 2 \\
\hline Pair 4 & 26 & 13 & 5 & 5 & 3 \\
\hline Pair 5 & 21 & 8 & 6 & 3 & 3 \\
\hline Pair 6 & 22 & 6 & 8 & 5 & 3 \\
\hline
\end{tabular}

\subsection{Playing as solving multiple mathematical problems}

So far we have shown the nature of several types of learning opportunities identified in our analysis. In particular, we have identified opportunities related to mathematical concepts associated to numeration, relation and change, geometry, position and measurement, which involve a wide range of mathematical contents that arise as essentials to attain the aims of the game. At the same time, we have shown that some of these learning opportunities arise in game situations where these concepts have to be addressed in a combined way. For this reason, we have developed plots showing game periods where students try to overcome the challenges in the game from a particular strategy which is sustained over time. In particular, we have identified several problem-solving processes in cycles of observation - planning - decision-making which are guided to solve the same game situation. In this manner, we observed that students try to solve several situations simultaneously and for long periods of time.

Figure 5 shows a graphic representation of the problem-solving cycles in a gameplay, where the brown bars represent the time interval in minutes in which the cycle occurs. In this gameplay, there is a long cycle of 25 minutes while students struggle with tower positioning to stop the faster enemies from reaching their objective. At the same time, students have some different problems, such as focusing all their attacking power in a concrete zone.

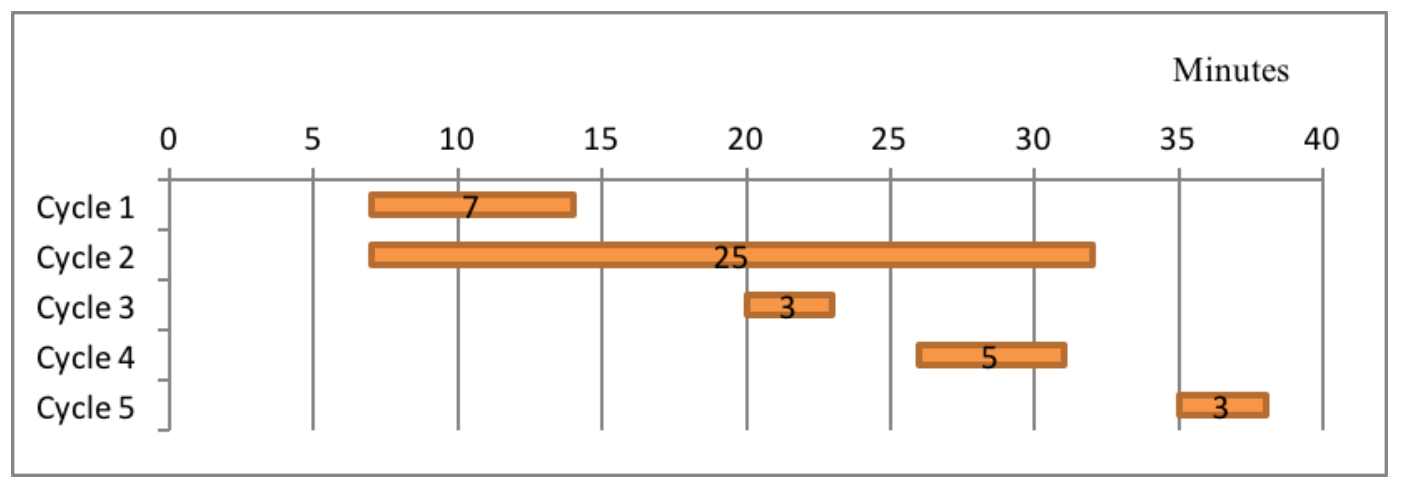

Figure 5. Observation-plannig-decision making cycles in a game and their duration in minutes

Since resolution cycles contain several problem-solving procedures and mathematical contents appear as key factors to make decisions, we understand that playing Vector Tower Defense 2 is a complex activity which fosters contextualized mathematical problem-solving. Since we have analysed the game played by students aged 10 to 12 , it is worth noting that we have not observed significant differences neither among the types of learning opportunities identified nor among the level of combination of the mathematical contents arised. 


\section{Discussion: Possibilities for redesigning the game}

The analysis of 10 to 12 year-old students while playing the video game Vector Tower Defense 2 shows that several mathematical learning opportunities can be identified during the game. It is worth noting that turning these opportunities into real learning is a genuine educational challenge. Thus, we consider that the use of the video game should be complemented with other educational strategies. Since the video game used in this study cannot be directly modified, we suggest designing another video game that uses the same mechanics but that also contains mathematical analysis tools to force players to formalise the mathematical contents dealt with during the game. To this end, we propose adding tools for displaying graphs of the damage processes caused by the different towers in the game and that they should be part of the game console. Specifically, we have incorporated various types of graphs in a preliminary version of this new game for the purpose of subsequently testing them on students [39].

In figure 6 we show one example of graph embedded in the game design. It displays instant damage caused by a tower over a brief period in a game and use different colours (lilac and yellow) to easily distinguish among the different rounds. This type of graph reveals how the tower is less effective in the second round where it appeared enemies of a different colour from the tower in the sense that it can do it less damage per second means that the enemy can be destroyed more slowly than the others.

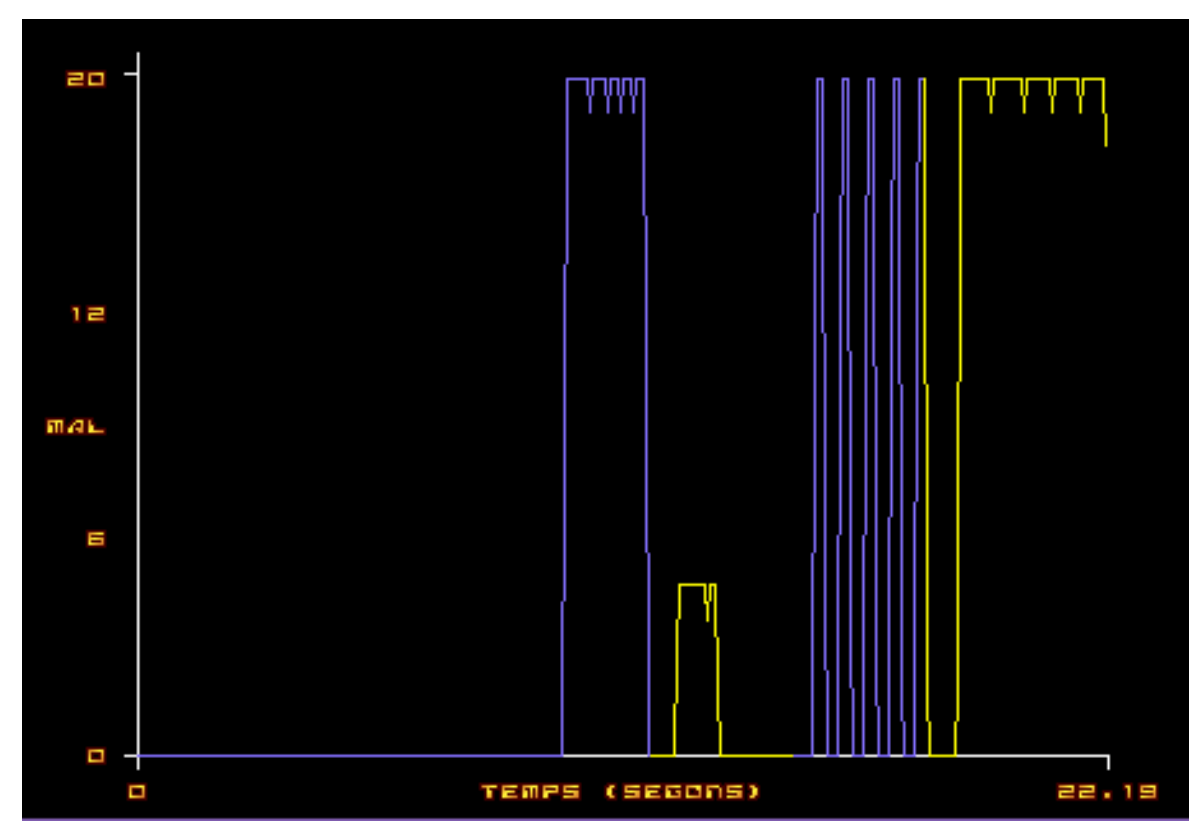

Figure 6. Graph of instant damage embedded on a new version of this classical game. For each round, a different colour showing the damage error is used

Another type of graph plots the accumulated damage done by a set of towers, as shown in Figure 7 . On this graph, each colour plot represents the damage of a different tower, so that one can see which tower has proved most effectiveness during the whole game. This assessment is based on examining and interpreting graphs showing complex information, thereby boosting mathematicaltype work using tools not included in the original game. 


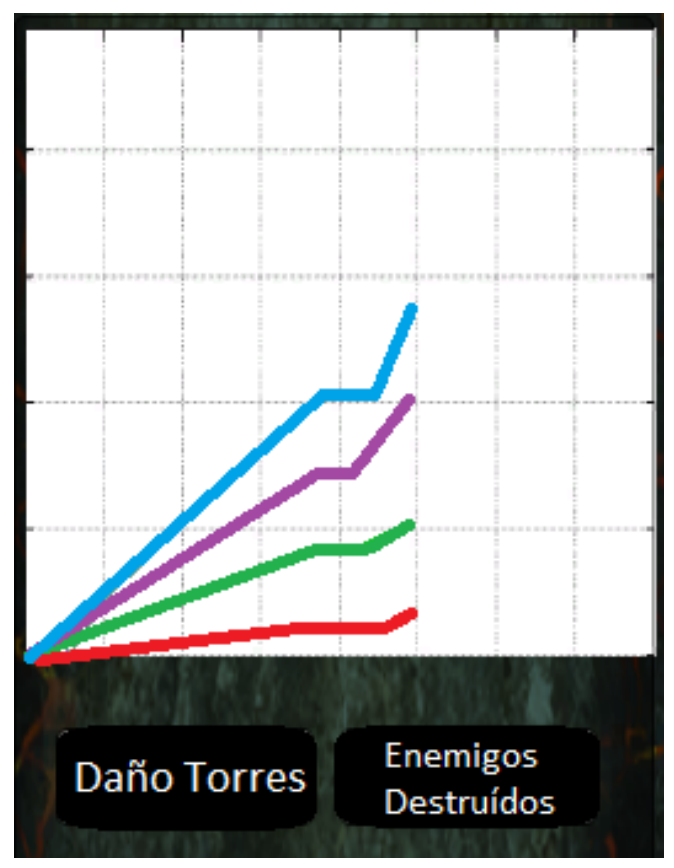

Figure 7. Graph of accumulated damage for several towers (each different colour corresponds to a different tower)

These new features should allow the professor to connect the students' video game performance with mathematical contents. The teacher can use a question guide that act as list of mathematical problems to help students solve game situations while mathematically analyze their in-game performance, with the help of the mathematical tools added.

This is a first step towards consolidating this kind of video games as an educational tool that should be explored in further studies. The mathematical tools to understand the game can already be found in some simulation or strategy commercial video games with a high level of gameplay complexity (such as Starcraft 2, Blizzard, 2010). Due to the complexity of these simulation or strategy games, the learning curve for the students is too high to be useful as classroom learning tools. From our point of view, a redesign of simpler video games could provide more effective learning tools and, in turn, this effectiveness should be studied.

\section{Conclusions}

A qualitative study of the way a Tower Defense game is played by students aged from 10 to 12 years shows that different types of mathematical learning opportunities result from game situations that involve several mathematical contents. These contents depend on the nature of the video game and could be different in other commercial video games, despite being of the same genre, since some of them strongly depend on design aspects like specific features of the towers. Thus, we observe that the game's characteristic features-which distinguish the game from others of the same genre- are key to motivating the students to work on specific mathematical contents, such as proporcionality or the study of functions.

Besides, we have observed that the game process is complex. The analysis shows a large amount of problem-solving processes that are not found to be isolated, but simultaneous. This gameplay can be beneficial to fostering the acquisition of mathematical competences, in particular problemsolving. Even so, the data analysis itself reveals that students do not try to mathematically solve problem situations that arise during the game. Consequently, the use of a video game in the classroom requires a specific intervention from the teacher, which is a project field that should be explored. This in turn requires suitable training and the presence of the teacher in the classroom to guide the activity, monitoring it and to evaluate the students' learning.

Another option is to endow the game with different design elements, turning it into a mathematical learning tool. This avenue has not been explored much and we believe that the elements contributed thus far constitute an initial approach to this type of video game. We consider that the instruments used in educational environments predetermine the students' cognitive processes - for 
example, a student does not measure in the same way if he/she has a ruler as if he/she does not have any measuring instrument- and the decision of introducing mathematical tools in a video game deals with learning intentionality. In particular, our point of view is focussed on helping the students to formalise the mathematical contents that arise during the video game. Finally, from the point of view of research in the field of mathematical education, we observe the difficulties experienced in the last decades to find formulas that allow to successfully work on problemsolving processes and heuristics learning in classrooms. These difficulties are already stated in the work of Schoenfeld [29],[30] who contributed to a framework of four different factors that affected students' abilities to solve problems, such as resources, heuristics, control and beliefs. From this point of view, strategy video games represent a new tool to be explored, since they offer a problem-solving environment for students, overcoming some of the barriers posed by common problem solving activities.

\section{References}

[1] Özyurt, Ö., Özyurt, H., Güven, B., \& Baki, A., The effects of UZWEBMAT on the probability unit achievement of Turkish eleventh grade students and the reasons for such effects, Computers \& Education, Vol. 75, 2014. http://dx.doi.org/10.1016/j.compedu.2014.02.005

[2] Randel, J. M., Morris, B. A., Wetzel, C. D., \& Whitehill, B. V., The effectiveness of games for educational purposes: A review of recent research, Simulation \& gaming, Vol. 23, Nr. 3, 1992. http://dx.doi.org/10.1177/1046878192233001

[3] Kebritchi, M., Hirumi, A., \& Bai, H., The effects of modern mathematics computer games on mathematics achievement and class motivation, Computers \& Education, Vol. 55, Nr. 2, 2010. http://dx.doi.org/10.1016/j.compedu.2010.02.007

[4] Van den Heuvel-Panhuizen, M., Kolovou, A., \& Robitzsch, A., Primary school students' strategies in early algebra problem solving supported by an online game, Educational Studies in Mathematics, Vol. 84, Nr. 3, 2013. http://dx.doi.org/10.1007/s10649-013-9483-5

[5] Rosas, R., Nussbaum, M., Cumsille, P., Marianov, V., Correa, M., Flores, P., Grau, V., Lagos, F., López, X., López, V., Rodriguez, P. \& Salinas M., Beyond Nintendo: design and assessment of educational video games for first and second grade students, Computers \& Education, Vol. 40, Nr. 1, 2003. http://dx.doi.org/10.1016/S0360-1315(02)00099-4

[6] Hamlen, K. R., Children's choices and strategies in video games, Computers in Human Behavior, Vol. 27, Nr. 1, 2011. http://dx.doi.org/10.1016/j.chb.2010.10.001

[7] Bottino, R. M., Ferlino, L., Ott, M., \& Tavella, M., Developing strategic and reasoning abilities with computer games at primary school level, Computers \& Education, Vol. 49, Nr. 4, 2007. http://dx.doi.org/10.1016/j.compedu.2006.02.003

[8] Panoutsopoulos, H., \& Sampson, D. G., A study on exploiting commercial digital games into school context, Journal of Educational Technology \& Society, Vol. 15, Nr. 1, 2012.

[9] Bishop, A., Mathematical enculturation: A cultural perspective on mathematics education, Dordrecht, Netherlands: Kluwer Academic Publishers, 1991.

[10] Salen, K., \& Zimmerman, E., Rules of play: Game design fundamentals, Cambridge, MA: MIT Press, 2004.

[11] Vygotsky, L. S., The development of higher forms of attention in childhood, Soviet Psychology, Vol. 18, Nr. 1, 1979.

[12]De Guzmán, M., Enseñanza de las ciencias y la matemática, Revista iberoamericana de educación, Vol. 43, 2007.

[13] Connolly, T. M., Boyle, E. A., MacArthur, E., Hainey, T., \& Boyle, J. M., A systematic literature review of empirical evidence on computer games and serious games, Computers \& Education, Vol. 59, Nr. 2, 2012. http://dx.doi.org/10.1016/j.compedu.2012.03.004

[14] Gros, B., Digital games in education: the design of games-based learning environments, Journal of Research on Technology in Education, Vol. 40, Nr. 1, 2007. http://dx.doi.org/10.1080/15391523.2007.10782494

[15] Charsky, D., From Edutainment to Serious Games: A change in the use of game characteristics, Games \& Culture, Vol. 5, Nr. $\quad 2, \quad 2010$. http://dx.doi.org/10.1177/1555412009354727 
[16] Ke, F., "A qualitative meta-analysis of computer games as learning tools", In Furdig R. E. (Ed.), Handbook of Research on Effective Electronic Gaming in Education, US: IGI Global, 2009. http://dx.doi.org/10.4018/978-1-59904-808-6.ch001

[17] Gee, J. P., What video games have to teach us about learning and literacy, Computers in Entertainment, Vol. 1, Nr. 1, 2003. http://dx.doi.org/10.1145/950566.950595

[18] Dickey, M. D., Engaging by design: How engagement strategies in popular computer and video games and inform instructional design, Educational Technology Research and Development, Vol. 53, 2005. http://dx.doi.org/10.1007/BF02504866

[19] Katmada, A., Mavridis, A., \& Tsiatsos, T., Implementing a Game for Supporting Learning in Mathematics, The Electronic Journal of e-Learning, Vol. 12, Nr. 3, 2014.

[20] Wouters, P., Van Nimwegen, C., Van Oostendorp, H., \& Van Der Spek, E. D., A metaanalysis of the cognitive and motivational effects of serious games, Journal of Educational Psychology, Vol. 105, Nr. 2, 2013. http://dx.doi.org/10.1037/a0031311

[21] Sitzmann, T., A meta-analytic examination of the instructional effectiveness of computerbased simulation games, Personnel Psychology, Vol. 64, 2011. http://dx.doi.org/10.1111/j.1744-6570.2011.01190.x

[22] Perrotta C., Featherstone G., Aston H., \& Houghton E., Game-based learning: Latest evidence and future directions, Slough, England: National Foundation for Educational Research, 2013.

[23] Baek, Y. K., What hinders teachers in using computer and video games in the classroom? Exploring factors inhibiting the uptake of computer and video games, CyberPsychology \& Behavior, Vol. 11, Nr. 4, 2008. http://dx.doi.org/10.1089/cpb.2008.0127

[24] Young, M. F., Slota, S., Cutter, A. B., Jalette, G., Mullin, G., Lai, B., Simeoni, Z., Tran, M., \& Yukhymenko, M., Our princess is in another castle a review of trends in serious gaming for education, Review of educational research, Vol. 82, Nr. $1,2012$. http://dx.doi.org/10.3102/0034654312436980

[25] Chow, A. F., Woodford, K. C., \& Maes, J., Deal or no deal: using games to improve students learning, retention and decision making, International Journal of Mathematical Education in $\begin{array}{llllll}\text { Science } \quad \text { and } & \text { Technology, } & \text { Vol. }\end{array}$ http://dx.doi.org/10.1080/0020739X.2010.519796

[26] Nejem, K. M., \& Muhanna, W., The effect of using computer games in teaching mathematics on developing the number sense of fourth grade students, Educational Research and Reviews, Vol. 8, Nr. 16, 2013. http://dx.doi.org/10.5897/ERR012.143

[27] Harris, A., Yuill, N., \& Luckin, R., The influence of context-specific and dispositional achievement goals on children's paired collaborative interaction, British Journal of Educational Psychology, Vol. 78, 2008. doi:10.1348/000709907X267067

[28] Grugnetti, L., \& Jaquet, F., A mathematical competition as a problem solving and a mathematical education experience, Journal of Mathematical Behavior, Vol. 24, Nr. 3, 2005. http://dx.doi.org/10.1016/j.jmathb.2005.09.012

[29] Schoenfeld, A. H., Mathematical problem solving, Academic Press, 1985.

[30] Schoenfeld, A. H., "Learning to think mathematically: Problem solving, metacognition, and sense-making in mathematics", In Grouws, D. (Ed.), Handbook for research on mathematics teaching and learning, New York: MacMillan, 1992.

[31] National Council of Teachers of Mathematics, Principles and Standards for school mathematics, Reston: NCTM, 2000.

[32] Lesh, R., \& Zawojewski, J., "Problem-solving and modelling”, In Lester, F. K. (Ed.), Second handbook of research on mathematics teaching and learning, Reston: NCTM, 2007.

[33] Lester, F. K., \& Kehle, P. E., "From problem-solving to modeling: The evolution of thinking about research on complex mathematical activity", In Lesh, R. \& Doerr, H. (Eds.), Beyond constructivism: Models and modeling perspectives on mathematics problem solving, learning, and teaching (pp. 501-518). Lawrence Erlbaum Associates, 2003.

[34] Pólya, G., How to solve it, Princeton: Princeton University Press, 1945.

[35] Verschaffel, L., Greer, B. \& De Corte, E., Making sense of word problems. Swets and Zietlinger Publishers, 2000.

[36] Engle, R. \& Conant, F., Guiding principles for fostering productive disciplinary engagement: Explaining emerging argument in a community of learner's classroom, Cognition and Instruction, Vol. 20, Nr. 4, 2002. http://dx.doi.org/10.1207/ S1532690XCI2004_1

[37] Van Den Heuvel-Panhuizen, M., The role of contexts in assessment problems in mathematics, For the Learning of Mathematics, Vol. 25, Nr. 2, 2005. 
[38] Cobb, P., y Whitenack, J. W., A method for conducting longitudinal analysis of classroom video recordings and transcripts, Educational Studies in Mathematics, Vol. 30, Nr. 3, 1996. http://dx.doi.org/10.1007/BF00304566

[39] Guzmán, D., Videojocs educatius: creació d'una plataforma per a l'anàlisi de les estratègies utilitzades a un joc de tipus Tower Defense, Master thesis, Barcelona: Universitat Autònoma de Barcelona, 2012. 